\title{
Evaluating Pedestrian and Cyclist Behaviour at a Level Crossing
}

\section{Lukas Hartwig ${ }^{a}$, Clemens Kaufmann ${ }^{a}$, Ralf Risser ${ }^{a}$, Christian Erbsmehl, Tom Landgraf ${ }^{b}$, Martin Urban ${ }^{b}$, Dominik Schreiber ${ }^{b}$}

${ }^{a}$ Factum OG, Hermann-Bahr Straße 9/11 1210 Vienna, Austria

${ }^{b}$ Fraunhofer IVI, Zeunerstraße 38, 01069 Dresden, Germany

ABSTRACT: The article gives an overview about the results of the use of a newly developed measurement technique in order to analyse the behaviour of road users at level crossings. For the test of the measurement technique a before/after design was chosen in order to evaluate the effects of a speed bump on the behaviour of road users and on safety at level crossings. The measurement technique combines the use of (1) an infrared camera and (2) conventional video recording. The use of an infrared camera allows the registration of variables such as speed, position, distance and acceleration independent of lighting conditions. A conventional camera includes recording of road users head movements on the basis of which one can conclude where their attention is directed.

Besides the analysis of changes in motorists'behaviour due to installation of a speed bump, data on the behaviour of vulnerable road users was also collected. The article concentrates especially on these results. It shows different forms of misconduct amongst the vulnerable road users that stems from different sources of error and could potentially lead to accidents. Crossings against red were observed as well as a negative effect of group size on the frequency of looking to the left and/or right.

Generally vulnerable road users were crossing the railway mostly alone followed by crossing in pairs. Bigger groups were also observed but were more an exception like school classes or groups of recreational cyclists.

The gaze behaviour of the vulnerable road users to the left and right hardly changed over the time and about two thirds of the pedestrians and cyclists were looking in at least one direction before crossing the railway. During the period without the speed bump eleven pedestrians and five cyclists were crossing the rail road while the red light was activated (none within the period where the speed bump was implemented - which might be due to the speed bump itself but cannot be ascribe to it with certainty).

It can be concluded that the presented measurement technique could be suitable to be included in evaluations of the behaviour of vulnerable road users to achieve a more comprehensive format, which includes night time observations, observation of vulnerable road user behaviour and estimation of the effect of a safety measure.

KEYWORDS: Level crossing, Safety evaluation, Behaviour, Automated measurement technique, Vulnerable Road Users, Night time measurements

\section{INTRODUCTION AND BACKGROUND}

In order to avoid accidents at railway crossings, some structural measures have been carried out in Austria in recent years. In order to systematically examine and to compare the effects on the behaviour of road users and the traffic safety at level crossings the project SESAM (Evaluierung der Sicherheit von Eisenbahnkreuzungen mittels automatischer Messmethoden - Safety evaluation at level crossings with the help of an automated measurement technique), funded by the OBB-Infra (Infrastructure Department of the Austrian National Railway) and the Ministry of Transport, Innovation and Technology (BMVIT) processed by the Austrian Research Promotion Agency (FFG) was carried out.

A measurement technique (a combination of video and infra-red camera) was tested at a level crossing in Lower Austria where a speed bump was temporarily installed. The decision for implementing a speed bump was taken by the local authorities 
in cooperation with OBB-Infra (Infrastructure Department of the Austrian National Railway). Data were collected before and directly after the installation of the speed bump and again three months later (without the speed bump - due to protests of the residents nearby the speed bump was removed after the second measurement period). Even though the speed bump was mainly aiming to change the behaviour of motorists, we want to show in this article that the developed measurement technique can also be employed to evaluate the behaviour of vulnerable road users (VRU). Therefore, we analyse the data on the behaviour of pedestrians and cyclists that was gathered alongside the data about motorists with regards to: a) the general behaviour when crossing the level crossing, b) misconduct that could potentially lead to accidents, and c) possible direct and indirect effects that the speed bump had on the behaviour of the VRU.

\section{PURPOSE}

SESAM had several goals: First of all to develop a standard for the evaluation of the effectiveness of traffic safety measures at level crossings. Based on that to develop a suitable measurement technique which can be used independently from the infrastructural situation or the type of protection (active or passive) at level crossings. And finally to test the standard and the measurement technique at a test location to see if it is possible to systematically examine the effects of a traffic safety measure on the behaviour of all road user groups and on traffic safety.

The purpose of the article is to present the results of the SESAM project with regard to vulnerable road users. Beside that the implementation of the speed bump has a greater effect on the behaviour of the motorised road users the authors want to show that with the here presented method also statements regarding the behaviour of vulnerable road users at level crossings can be made.

\section{THEORY OF BEHAVIOUR}

Fertner (2009) found that $66 \%$ of all respondents in his study perceived passive level crossings as dangerous. In an Austrian survey (Raml, 2012a), 31\% of the participants stated that they consider railway junctions more dangerous than road junctions. $82 \%$ of the interviewees experience passive level crossings as particularly dangerous.

However, accident statistics from different countries show that accidents at railway crossings are mainly caused by misconduct of road users. In the ÖBB accident statistics (2001-2005) (see Pripfl, 2009), 98\% of accidents in 2001-2005 are attributed to misconduct.

Based on the theory of the project MANEUVER (Development of Measures to Prevent Misconduct at Railway Crossings Using Traffic Psychology, Aigner-Breuss et al 2011), which was carried out as a preparatory work of the SESAM project, it becomes clear that the human factor plays a fundamental role in the causation of traffic accidents at level crossings. In this case not watching carefully or observing the situation and thus committing priority violations, without a reaction of the driver to the situation, are essential causes of accidents. Therefore, the model from the MANEUVER project was used to have a better understanding of the behaviour of road users at level crossings.

Behaviour in a given situation consists of three sub-processes: information - assessment and decision - action. In each sub-process both intentional and unintentional errors can happen.

a) In a certain situation the first available information is recorded and processed by the road users' sensory organs. Errors can happen due to habits distraction or visual illusion. The information and information associated with this situation from memory, form the basis for the second sub-process, namely the

b) evaluation of the circumstances. Here errors can be due to a lack of knowledge of rules and laws, compliance or stress. The evaluation leads to a decision and finally an

c) action in each situation.

The sources of errors with regard to level crossings are described in detail in the following:

\section{Source of error a) Information processing} and distractions

According to Grimm (1988), 50\% of accidents can be attributed to non-awareness or non-recognition of dangers. For traffic signs to be adequately perceived, the placement, font size, etc. must be according to the approaching speed of road users. However, an excess of information at the railroad crossing can lead to per- 
ceptual errors (RSSB 2011b). The immediate vicinity of the railway crossing plays also an important role for the perception and the distribution of attention. If there is e.g. a crossroads directly behind the railroad crossing, it will most likely attract the attention of the drivers and lead to a neglect of the railway crossing (Wigglesworth, 1976). Habits (crossing a level crossing regularly, due to a nearby living or working place) also play a major role in the perception of railway crossings (RSSB, 2008).

Distraction can be cited as another major cause of accidents. It means that the entire traffic situation is not given the necessary and undivided attention that would be needed to perceive, process and evaluate all relevant aspects. According to NTSB (1998, cited in Pripfl, 2009), in general $20 \%$ of accidents are caused by distraction. In the study by Fertner (2009), rush was named on first place when asked what distracted drivers most. In an Austrian survey (Raml, 2012a), about $25 \%$ of the interviewees stated that they are distracted due to the fact that they are being in a hurry.

\section{Source of error b) Assessment and decision error}

In general, $40 \%$ of accidents can be attributed to incorrect risk assessment and consequently wrong decisions (Grimm, 1988). Other key aspects concern the assessment of the traffic situation or driving situation (Pripfl, 2009, see also RSSB, 2008). A few drivers would enter the railway intersection despite a blocked exit (for example, by a truck) (RSSB, 2011a). Berg et al. (1986) found in their study that in $18 \%$ decision errors caused an accident, e.g. inexperienced drivers did not pay attention to the slippery road surface (an evaluation error that led to a wrong decision). Experience-based risk assessment (Pripfl, 2009, see also Raml, 2012b) also plays an important role in the use of railway crossings: the road user judges a situation on the basis of their experience at other railway junctions and might conclude that there is enough time left to cross the railway intersection when the light signal has just jumped to red. Also, most road users are unaware that a second train could come (RSSB 2011b). In a US study that looked at a railroad crossing in rural areas, $66 \%$ of drivers crossed the tracks despite an activated red light signal and an approaching train (Meeker and Barr, 1989). Most drivers slowed down or stopped before crossing, but there were also drivers who crossed the tracks with unreduced speed. The authors deduced from the results of the study that light signals or in general active protec- tion at railway crossings may cause drivers to decide for themselves whether to cross or to wait.

Personal factors, such as anger or time pressure can not only lead to distraction and thus to perception errors, but also to wrong decision at level crossings. Caird et al. (2002) researched that $1.6 \%$ of accidents at level crossings are due to disregard of full barriers and 3.6\% due to by-passing of half-barriers. When the waiting time is perceived to be very long, there is a growing willingness to ignore the rules: $40 \%$ of drivers say they might be ready to disregard a red light (Ellinghaus and Steinbrecher, 2006). On average, test persons in an Austrian computer simulation study (Dinhobl \& Lengger 2012 in AignerBreuss et al 2011) found the waiting times for light signal systems from 116 seconds - 114 seconds for half-barriers and 168 seconds for full barriers - too long. $18 \%$ of the drivers are willing to drive around half-barriers after long waiting times (Ellinghaus and Steinbrecher, 2006). In the case of half-barriers, some people seem to think, "I can decide for myself how long I want to wait" (Ellinghaus and Steinbrecher, 2006). The level crossing is experienced as an obstacle, as a disturbance of the intended movement. Also, lack of knowledge about traffic rules leads to wrong decisions. Nussbaumer and Nitsche (2007) showed that the majority of the surveyed drivers feel inadequately informed about the rules of conduct at level crossings, even though they learned those rules in drivers' education. At Ellinghaus and Steinbrecher (2006), 33\% of road users believe they do not have to stop at a red flashing light.

\section{Source of error c) Action error}

Unintentional failure results, on the one hand, from erroneous or inadequate information processing (e.g. distraction). On the other hand, misconduct may occur, through the deliberate violation of a rule. This can result from a generally low willingness to follow rules or from a wrong assessment or decision in the situation. Knowles and Tischler (2010) showed that $8 \%$ of the interviewees said they had driven against a red light over a railway intersection. This was due to too late detection of the light signal, too high approach speed to stop in time and that no train was in sight.

Within the SESAM project for the observed data respectively errors of the road users were categorised in one of the three sub-processes. So it was possible to see in which process the most errors are happening in order to prepare solution to counter them. 


\section{SELECTED SITE}

The site as well as the implemented safety measurement (bump) was chosen before the start of the project by the OBB-Infra (Infrastructure Department of the Austrian National Railway). The level crossing Pernitz / Wipfelhofstraße is actively protected with a light signal. The light signal turns to red about 20 seconds before the train enters the crossing and goes out about five seconds after the train has passed through. The level crossing is indicated by traffic signs and ground markings (white stripes) and is illuminated at night. Looking to the north there is a train station on the left side. Every hour two passenger trains are stopping at this railway station.

A dual carriageway (one lane in each direction) leads to and from the level crossing. The width of the lane to the north is 2.8 meters and to the south 3.1 meters. Looking south, there is an exit to a parking lot about 10 meters before the level crossing on the right. After the level crossing a dead-end street also branches off to the right. Cyclists can access the Piestingtal cycle path from there. 50 meters further to the south another street branches off to the left to a residential area.

On both sides of the road there is a sidewalk. Looking south, the left-hand sidewalk may also be used by cyclists. After the level crossing, the mixed pedestrian/cycle path ends after three meters. Cyclists then have to cross the road following the cycle path into the dead-end street. On the right side the sidewalk is interrupted by the dead-end street.

All traffic facilities are paved and in good condition. The speed limit is $30 \mathrm{kph}$ in both directions. The markings on the pavement indicating the level crossing (white stripes) are already a bit worn, but still well visible.

Looking north, the length of the viewing distance directly to the level crossing and especially the light signal is more than 200 meters. Looking south it is about 50 meters, because the road only then branches off from the town's main road. Looking south there is a maintenance house on the right side which obstructs the view onto the railway tracks. 20 meters before the level crossing one has a clear view on the train tracks to the left. Looking north there are no obstructions in the line of sight on the railway tracks at about 15 meters before the level crossing.

\section{Speed bump}

One hard rubber speed bump with a height of $60 \mathrm{~mm}$ was implemented 20 meters before the level crossing on each side (https://shop.neuhauser-vt. com/c/47/a/10698/Warn--und-Temposchwellen/ Tempo-Hemmschwelle-bis-10-km-h-schwarz. html;JSESSIONID=a44a0bf5-48d5-47b9-b85f54d69f88f646). The speed bump was implemented over the full length of the road in order to avoid that cars could drive around.

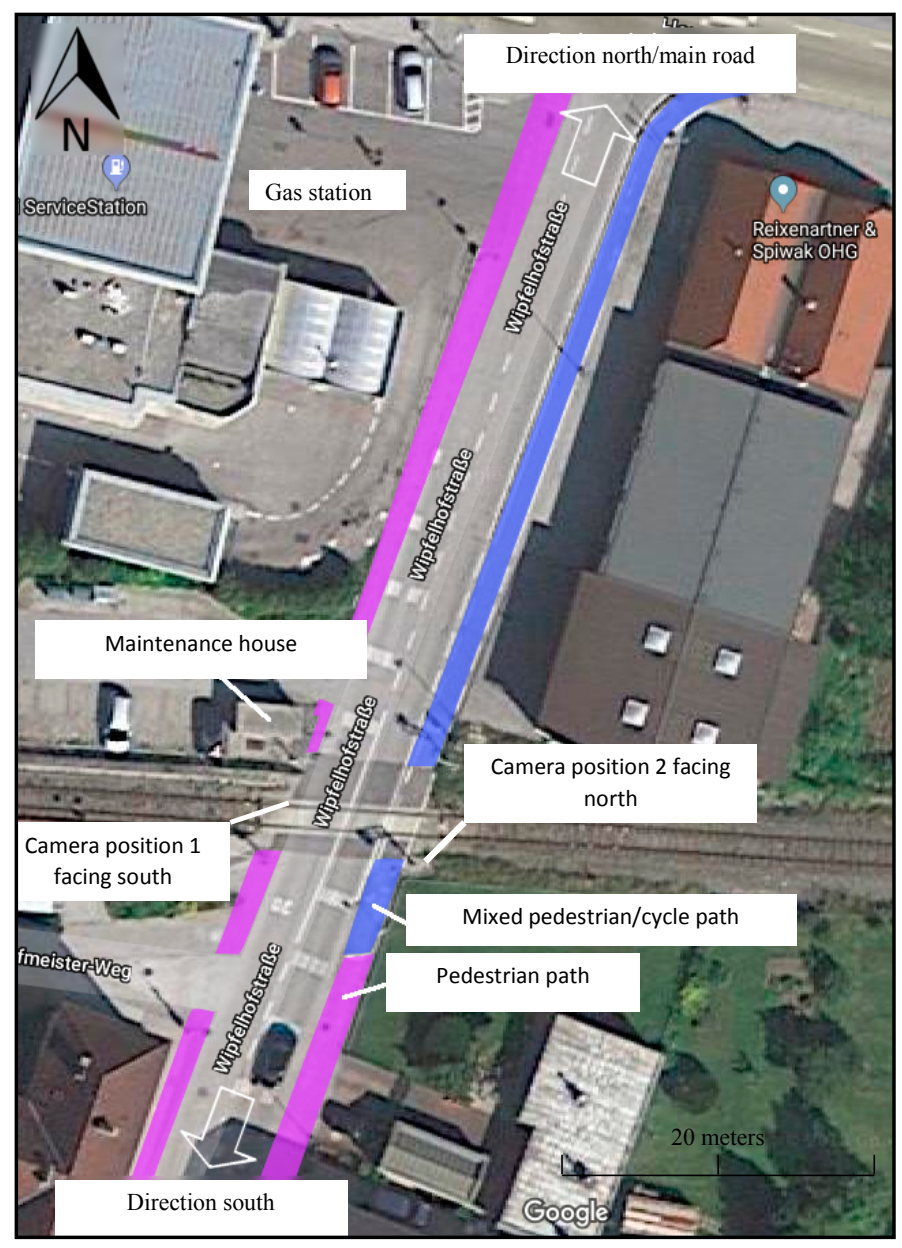

Figure 1: Map with an overview of the testside

\section{METHOD}

The measurement technique which was developed within the SESAM projects combines the use of (1) an infrared camera and (2) a conventional video camera. The use of infrared cameras that until now have been employed primarily in urban areas (at intersections), allows the registration of variables such as speed, position, distance and acceleration behaviour for all road users. Head movements of the road users, based on which one can deduce where the attention is directed, and the general behaviour of vulnerable road users was recorded with an additional video camera. The general behaviour included where they walked, if they were walking alone or in groups, ac- 
tivities such as talking on the phone or to somebody else, if they were walking or running etc. The video data was later evaluated by observers who marked different behaviour on an evaluation sheet.

Two camera systems, consisting of an infrared camera, a video camera and small PC with an external hard drive were installed at the railway crossing. One system could be connected to the electric grid while the power for the other came from batteries that had to be periodically replaced and recharged. The data were captured using software that was developed by Fraunhofer IVI and that both records and compresses the camera feed and saves it encrypted on the external hard drive. Furthermore, another programme is monitoring these processes and reacts with a system reboot should an error be detected.

\subsection{Functional principle of data collection with the infrared camera}

The infrared cameras used in this project detect electromagnetic radiation in the thermal spectral range (wavelength 8-15 $\mu \mathrm{m}$ ) with the help of a Bolometer sensor. In the thermal spectrum all objects emit radiation themselves rather than just reflecting it like in the visible spectrum. That makes capturing objects without the existence of an external light source at night possible. The infrared radiation of different intensity captured by the camera is converted into a black-and-white image to make it comprehensible for the observer. Details like facial features or number plates are not recognizable, therefore the recordings are natively anonymous. That made sure that in the case of data theft no person-related data like faces and number plates would be compromised.

Materials have different optical properties in the thermal spectral range than in the visible range. Water and glass are not transparent but emit and reflect radiation. Therefore it is not possible to see through it with an infrared camera.

\subsection{Functional principle of data collection with the video camera}

In order to be able to look through the windscreen of cars using the railway crossing and to analyse the gaze behaviour of the road users, additional video data was recorded with the help of a waterproof high resolution RGB video camera and were encrypted before being stored on the hard drive. The data was stored password protected and only the observers had access to it.

\subsection{Installation of the camera systems}

Both systems were built into one waterproof and lockable casing each and mounted on the pole of the railway crossing sign that provided a firm installation mount and an excellent vantage point for the cameras that is mostly out of reach of vandalism. The cameras were aligned in a way that users of the railway crossing could be observed on their entire approach until the very edge of the rails. Camera 1 was facing south while Camera 2 was facing north (see figure 2.)

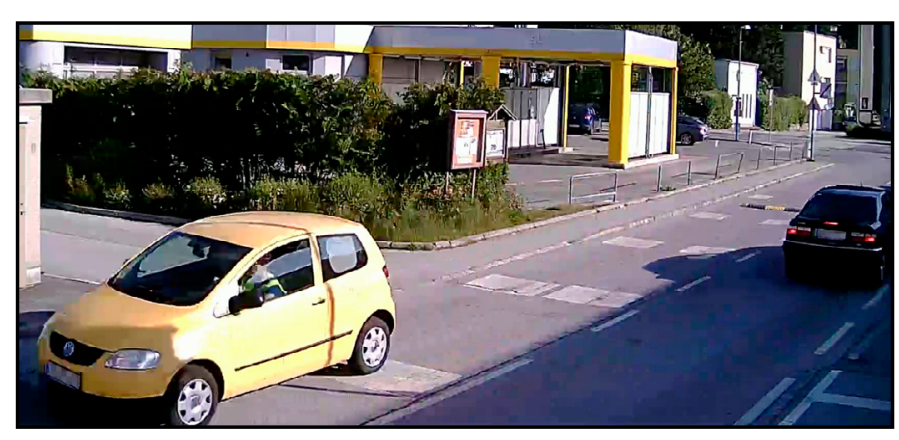

Figure 2: Perspective from camera position 2 facing north

\section{DATA ANALYSIS}

According to an explorative procedure, in which relevant influencing factors are not sufficiently known in advance, but are discovered during the ongoing evaluation, the evaluation of whole days was prioritised in the periods 1 and 2 . These were selected according to the completeness of the existing video material. In addition, care was taken to have different work and weekend days in the sample in order to observe effects related to commuting.

The data (including night times) of the infrared camera was analysed using automated detection and tracking of objects through comparison of single frames. This data mainly was used to evaluate the behaviour of motorised road users, which will not be presented in detail in this article. With the help of a statistical background estimator, potential objects were differentiated from the background. If two sufficiently similar objects were registered with reference to size, coordinates, direction of travel and speed, their calculated locations were combined to form a trajectory. Objects were differentiated between types (vehicle types, pedestrians, cyclists, animals) and their speed and position at various stages of their approach was registered. Similar trajectories were later combined to avoid multiply registering vehicles whose trajectories were fragmented. The ad- 
vantages of the method are that with a single infrared camera speeds, position and the type of the object (vehicle type, pedestrians, cyclists) in the approaching area can be detected. Automated detection and tracking of objects is also possible during the night and in all weather conditions. While other methods such as radar only measure speed but not e.g. if it is a truck or a passenger car. Also the simple installation of the system is an advantage as only one camera is needed to cover the whole area of interest. The drawback would be that the speed of objects which are further away can only be measured within a range of $+/-2 \mathrm{kph}$. Furthermore in the here presented study the maintenance effort was quite high as the hard discs and batteries (for the camera without direct connection to the electricity line) had to be changed every third day (see also chapter 11).

For the evaluation of the video records the data of camera 2 facing north were used. As the video data was analysed manually and due to time restrictions a manageable but representative sample out of the recorded videos had to be drawn. Since no significant influence of the time on the gaze behaviour (people looking left or right before crossing the level crossing) had been shown in the evaluation of the measurements 1 and 2 , for measurement 3 , hours were selected for analysis at which the looking behaviour was best recognizable due to the exposure of light, in this case from about 8:30 until $10: 30$ and from $16: 30$ to $18: 30$. At these times, the low sun optimally illuminated the vehicle interior and head movements were more easily recognizable. These times were analysed for each day of the week. In addition, a few days were analysed entirely. For the data analysis only the above mentioned hours for all three measurements periods were used.

The analysed sample consisted of more than 500 hours data from the infrared camera (the complete data recorded during the measurement period except the times were there was a failure in the system) and almost 150 hours of video material (which were chosen according to the criteria stated above) (Table 1).

Table 1: Hours of recording used for data analysis

\begin{tabular}{ccc}
\hline Measurement period & Infrared camera & Video camera \\
\hline 1 & 131 & 57 \\
2 & 124 & 23 \\
3 & 251 & 64 \\
\hline Total hours & $\mathbf{5 0 6}$ & $\mathbf{1 4 4}$ \\
\hline
\end{tabular}

\section{RESEARCH DESIGN}

\section{Research design}

For the naïve evaluation study a before/after design was chosen. Within the first period (without the speed bump) data was collected in order to establish a baseline for the comparison with the other two measurement periods. Directly after the first period the speed bump was implemented and the second measurement period (with the speed bump) was started. Between the second and third period the speed bump was removed due to protests of the residents living and working nearby. People were of the opinion that the speed bump is useless and uncomfortable to drive over. Therefore the data of the third period, collected three months after the first period, was still used as a comparison for the data from the other two measurement periods but especially to confirm the data of the first period.

Table 2 gives an overview on the date and duration of the three measurement periods.

Table 2: Overview of the measurement periods and duration of measurement

\begin{tabular}{lc}
\hline Measurement period & $\begin{array}{l}\text { Number of days } \\
\text { of measurement }\end{array}$ \\
\hline Period 1: & 10 \\
Before implementation of the measure & \\
as a baseline (data which was used to \\
compare with the data of the $2^{\text {nd }}$ and $3^{\text {rd }}$ \\
measurement period) \\
(May 2017) \\
Period 2: \\
$\begin{array}{l}\text { Directly after the implementation for } \\
\text { comparison }\end{array}$ \\
June 2017 \\
Period 3: \\
Three months after the measure had \\
been removed again for comparison with \\
the baseline \\
September 2017
\end{tabular}

\section{Sample description}

It is assumed that in general the change in the number of observed road users might mainly differ due to the weather situation during the three measurement periods. No other data were available to verify if road users were using other roads to avoid the speed bump before the level crossing The share of pedestrians and cyclists was not constant in all measurement periods. While in the first period, the proportion of pedestrians in the sample was nine percent, this in- 
Table 3: Number of pedestrians and cyclists per period of measurement

\begin{tabular}{|c|c|c|c|c|c|c|}
\hline & \multicolumn{2}{|c|}{ 1st Period } & \multicolumn{2}{|c|}{ 2nd Period } & \multicolumn{2}{|c|}{ 3rd Period } \\
\hline & Count & $\%$ & Count & $\%$ & Count & $\%$ \\
\hline Pedestrians & 334 & 9.1 & 258 & 11.6 & 616 & 13.0 \\
\hline Cyclists & 299 & 8.1 & 165 & 7.4 & 207 & 4.4 \\
\hline Total & 3,684 & 100 & 2,229 & 100 & 4,728 & 100 \\
\hline Number of hours analysed & \multicolumn{2}{|c|}{57} & \multicolumn{2}{|c|}{23} & \multicolumn{2}{|c|}{64} \\
\hline
\end{tabular}

creased to 11.6 percent for the second period and 13 percent for the third. The proportion of cyclists decreased from 8.1 percent during the first period to 7.4 percent during the second period and finally to 4.4 percent in the third.

The decreasing proportion of cyclists can easily be explained by the weather conditions. The number of rainy days was significantly higher during the third period than during the previous two, so some potential cyclists might have chosen to use other modes instead.

Table 4: Total rainy days per measuring period

\begin{tabular}{ll}
\hline Period & Rainy days \\
\hline 1 & 1 of 10 \\
2 & 1 of 9 \\
3 & 4 of 11 \\
\hline
\end{tabular}

\section{RESULTS}

The results are analysed with a special focus on the observed behaviour of the vulnerable road users in order to determine if it is a safe behaviour and to identify any influencing factors.

When analysing the proportions over the day, the proportion of pedestrians (figure 3 ) is relatively high in the morning hours (7:00 and 8:00) with between 15 and 20 percent. These are likely to be mainly commuters who walk to the train. It then drops to below ten percent by midday (13:00) and rises to as much as 20 percent in the next two hours. From 15:00, the proportion of pedestrians is between six and 14 percent.

The proportion of cyclists (figure 4 ) in the morning hours is between five and seven percent. It then rises until 12:00 up to 13 percent and drops again until 16:00 to about six percent. While in the second and third periods the level remains the same between 16:00 and 17:00 with five percent, the proportion of cyclists in the first measuring period rises to almost ten percent and then drops back to five percent at 18:00. During the second period, the proportion of cyclists increased to over ten percent until 19:00, while in the third measuring period the proportion decreased below two percent.

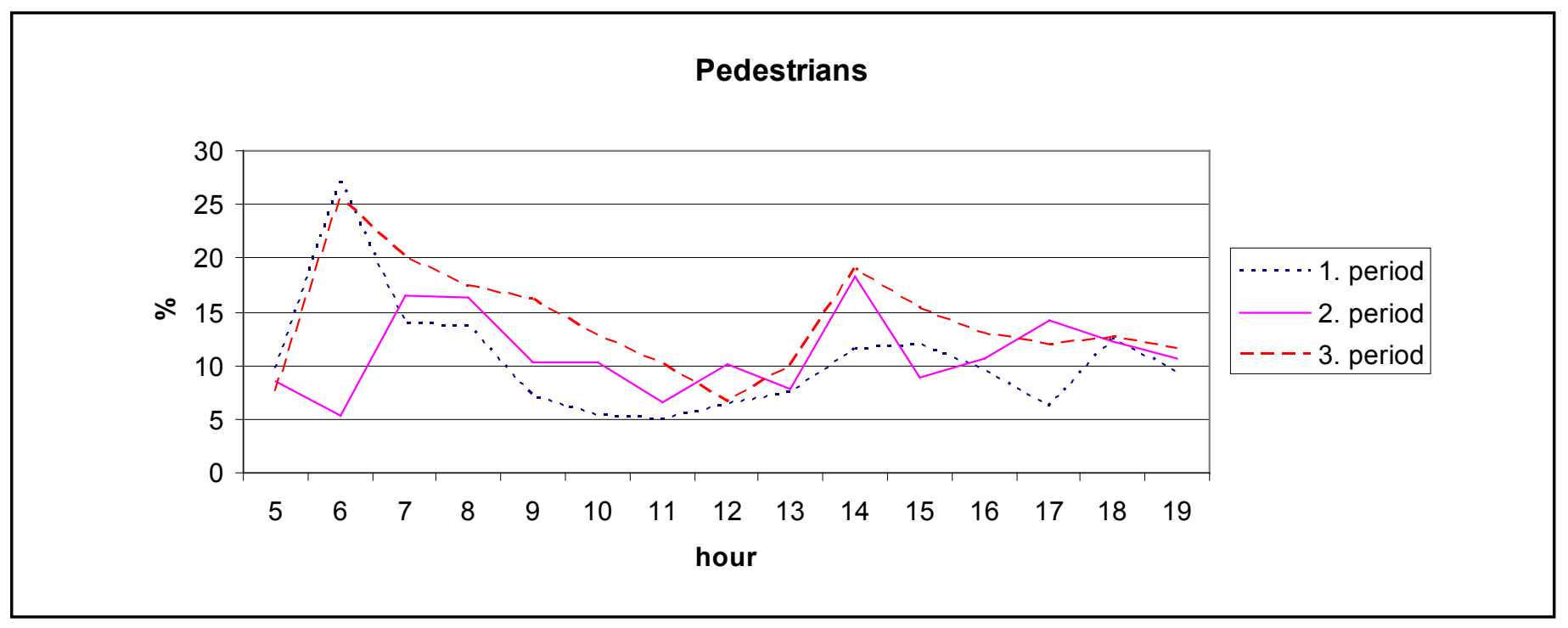

Figure 3: Percentage of pedestrians per hour of the day 


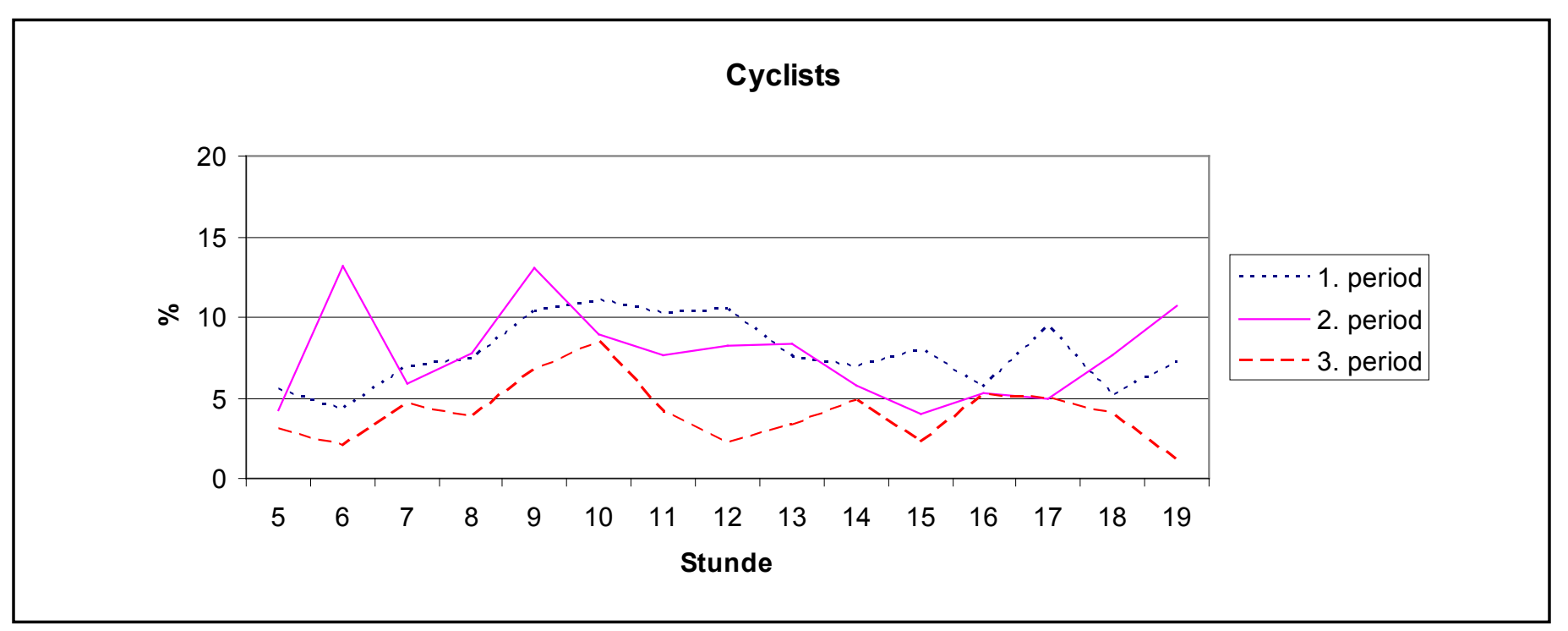

Figure 4: Percentage of cyclists per hour of the day

\section{Position of the road users traversing the level crossing}

With regard to the position at which the road users cross the level crossing, the following can be stated: In principle, the proportions of the road users for the respective position at which they cross the level crossing remain the same for all three recording periods (one exception being the cyclists). 80 percent of pedestrians use the right sidewalk and only 10 percent the left sidewalk. Seven percent (third measurement) and ten percent (first and second measurements) of pedestrians walk on the carriageway before crossing the level crossing, mostly while crossing the road at the same time.

As mentioned above, the proportion of cyclists and their position when crossing the level crossing changed over the three periods. While the percentage of people riding on the far right remains relatively constant at between 14 and 16 percent, during the first and second recording periods 20 percent of them ride on the mixed cycle and footpath on the left. On the other hand, the proportion of cyclists riding on the road increases to 80 percent in the third period, while in the other two periods those riding on the road account for only 60 percent (difference is sta- tistically significant, $\mathrm{p}<0.05)$. Since, as mentioned above, the proportion of cyclists in the modal split in the third period is lower probably due to more rainy days, it can be assumed that in the third period predominantly everyday cyclists are riding and are using the carriageway in order to move faster.

\section{Speed}

Figure 5 shows the speed distribution of cyclists in relation to the distance to the level crossing. For camera 1 (cyclists coming from the south) the speed distribution in the first and third period is very similar (slight braking towards the level crossing), while during the second period cyclists who were also using the road, braked slightly at the point where the speed bump was implemented ( $20 \mathrm{~m}$ before the level crossing) in order to pass on the side of it. For camera 2 the speed distribution shows that cyclists are braking also 25 meters before the level crossing in the first and second measurement period but not during the third period. This might be due to the fact that cyclists also have to give priority to cars coming out of the parking lot on the right side. During the third period the whole road was refurbished and old road markings were erased. This might have given

Table 5: Position of railway crossing users in percent

\begin{tabular}{l|ccc|ccc|ccc}
\hline & \multicolumn{3}{|c|}{ 1st Period } & \multicolumn{3}{c|}{ 2nd Period } & \multicolumn{3}{c}{ 3rd Period } \\
\cline { 2 - 10 } & On the right & Road & On the left & On the right & Road & On the left & On the right & Road & On the left \\
\hline Pedestrians & 80.8 & 9.9 & 9.3 & 77.9 & 10.5 & 11.6 & 82.0 & 6.8 & 11.2 \\
Cyclists & 16.4 & 63.5 & 20.1 & 15.8 & 61.8 & 22.4 & 14.5 & 80.7 & 4.8 \\
\hline
\end{tabular}




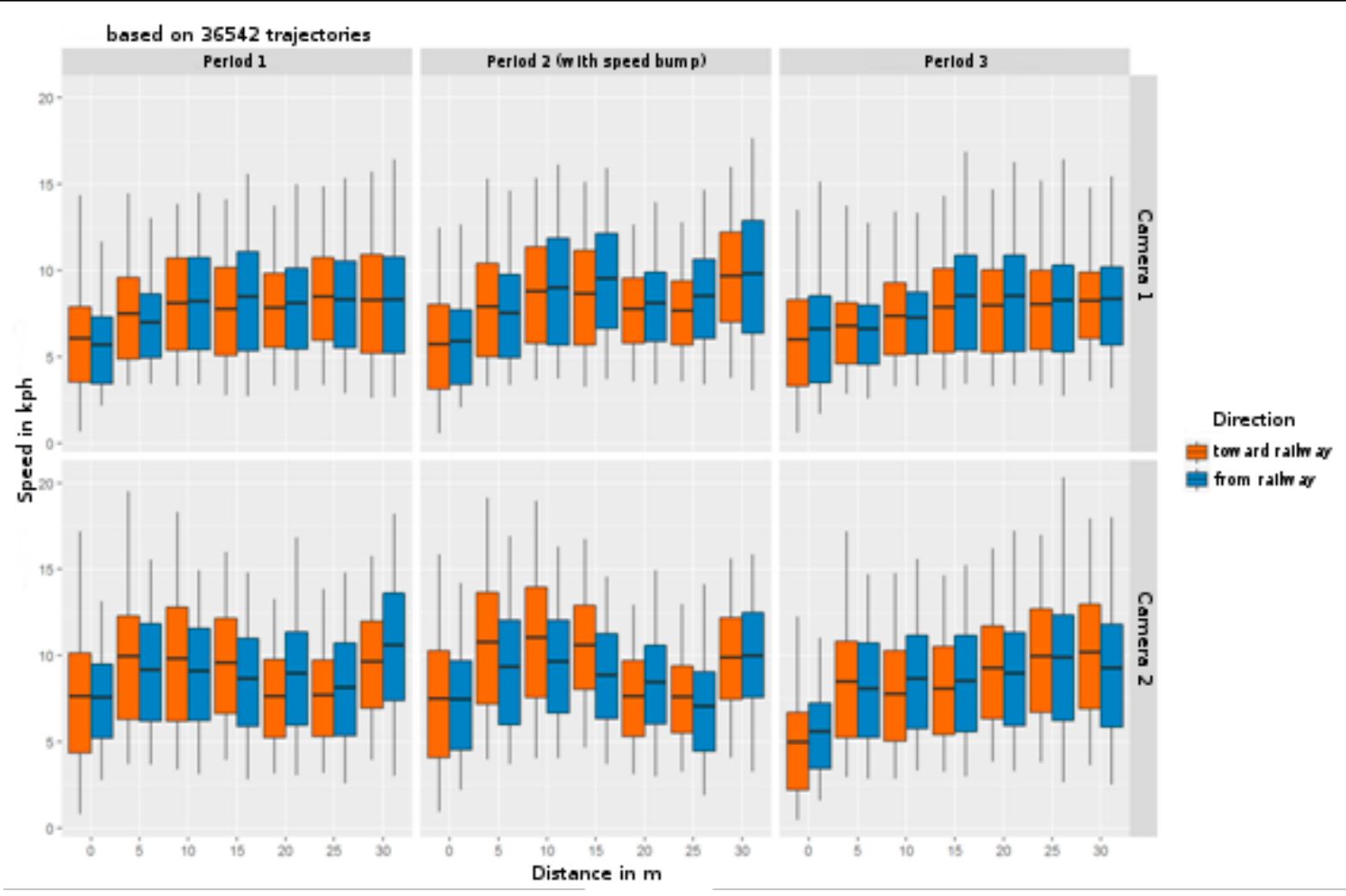

Figure 5: Speed distribution of cyclists in relation to distance to crossing

the impression that road users on the main road have the priority over the side road.

As the speed bump did not affect the behaviour of pedestrians at all, their speed distribution is expectedly very similar for all three measurement periods.

\section{Group sizes}

Pedestrians (table 6) crossed the railway intersection alone between 69 percent in the first and 61 percent in the third period. The proportion of groups of two crossing the railway junction is about one fifth in the first period and a quarter in the other two periods.
Most larger groups (4 and more) of pedestrians were observed in the third period. Otherwise, the proportions of the groups in the three periods were about the same.

Cyclists who were riding alone were registered least frequently during the first period (68 percent). In the second and third recording periods, this proportion increased to about three quarters. Larger groups of cyclists (4 or more) were observed in the first period, otherwise the proportions of the other group sizes between the three periods are also approximately the same.

Table 6: Crossing of the railway line in percent

\begin{tabular}{llllll}
\hline Group size & Alone & Two & Three & Four or more & Total \\
\hline Pedestrians & & & & & \\
\hline 1st Period & 68.9 & 19.2 & 8.4 & 3.6 & 100 \\
2nd Period & 65.1 & 24.4 & 6.6 & 3.9 & 100 \\
3rd Period & 61.4 & 24.5 & 7.8 & 6.3 & 100 \\
\hline Cyclists & & & & & 100 \\
\hline 1st Period & 68.2 & 19.7 & 4.7 & 7.4 & 100 \\
2nd Period & 75.2 & 17.0 & 4.8 & 3.0 & 100 \\
3rd Period & 74.4 & 17.4 & 5.3 & 2.9 & \\
\hline
\end{tabular}




\section{Gaze behaviour}

In the evaluation of the gaze behaviour, a gaze was counted, when it was observed that a road user turned their head to the left and/or right before crossing. Only the peak times between 8 and 10 o'clock and 16 and 18 o'clock were used for a better comparability of the data. The gaze behaviour of pedestrians and cyclists remained the same for all three periods, namely at a level of about two-thirds (Table 7). Reasons for not looking were not systematically evaluated but the observations showed that pedestrians were distracted by conversions, texting or talking on the phone (see table 12).

In a closer examination of the direction, in which the road users were looking, it becomes apparent that vulnerable road users at all times, look mainly to the right, followed by looking in both directions. This can be explained by the fact that on the right side next to the level crossing there is a house, which makes a head turn necessary in order to look along the railway tracks behind it. On the left side, the visibility is relatively better and can rather be covered by eye movements.

The gaze behaviour of groups can be described as follows: Bigger pedestrian and cyclist groups are looking less often than when walking or cycling alone. This applies to all three periods.

\section{Crossing against red and other misconduct}

Six red light crossings of vulnerable road users were registered in the first period and eleven in the third. No red light crossings were observed dur-

Table 7: Gaze behaviour of railway crossing users in percent

\begin{tabular}{l|ccc|ccc|ccc}
\hline & \multicolumn{3}{|c|}{ 1st Period } & \multicolumn{2}{c|}{ 2nd Period } & \multicolumn{2}{c}{ 3rd Period } \\
\cline { 2 - 10 } & $\begin{array}{c}\text { Gaze in at least } \\
\text { one direction }\end{array}$ & $\begin{array}{c}\text { No } \\
\text { gaze }\end{array}$ & $\begin{array}{c}\text { not } \\
\text { visible }\end{array}$ & $\begin{array}{c}\text { Gaze in at least } \\
\text { one direction }\end{array}$ & $\begin{array}{c}\text { No } \\
\text { gaze }\end{array}$ & $\begin{array}{c}\text { not } \\
\text { visible }\end{array}$ & $\begin{array}{c}\text { Gaze in at least } \\
\text { one direction }\end{array}$ & $\begin{array}{c}\text { No } \\
\text { gaze }\end{array}$ & $\begin{array}{c}\text { not } \\
\text { visible }\end{array}$ \\
\hline Pedestrians & 65.7 & 24.5 & 9.8 & 62.4 & 30.5 & 7.1 & 67.7 & 25.3 & 7.1 \\
Cyclists & 61.6 & 26.1 & 12.3 & 68.2 & 27.3 & 4.5 & 69.2 & 23.1 & 7.7 \\
\hline
\end{tabular}

Table 8: Direction of gaze while crossing in percent

\begin{tabular}{|c|c|c|c|c|c|c|c|c|c|}
\hline & \multicolumn{3}{|c|}{ 1st Period } & \multicolumn{3}{|c|}{ 2nd Period } & \multicolumn{3}{|c|}{ 3rd Period } \\
\hline & $\begin{array}{l}\text { Only to } \\
\text { the left }\end{array}$ & $\begin{array}{l}\text { Only to } \\
\text { the right }\end{array}$ & $\begin{array}{c}\text { Both } \\
\text { directions }\end{array}$ & $\begin{array}{l}\text { Only to } \\
\text { the left }\end{array}$ & $\begin{array}{l}\text { Only to } \\
\text { the right }\end{array}$ & $\begin{array}{c}\text { Both } \\
\text { directions }\end{array}$ & $\begin{array}{l}\text { Only to } \\
\text { the left }\end{array}$ & $\begin{array}{l}\text { Only to } \\
\text { the right }\end{array}$ & $\begin{array}{c}\text { Both } \\
\text { directions }\end{array}$ \\
\hline Pedestrians & 20.2 & 51.1 & 28.7 & 12.5 & 52.3 & 35.2 & 14.2 & 58.2 & 27.6 \\
\hline Cyclists & 12.9 & 71.8 & 15.3 & 11.7 & 70.0 & 18.3 & 9.3 & 63.9 & 26.9 \\
\hline
\end{tabular}

Table 9: Percentage of gaze behaviour while crossing in groups

\begin{tabular}{|c|c|c|c|c|c|c|c|c|c|c|}
\hline & & \multicolumn{3}{|c|}{ 1st Period } & \multicolumn{3}{|c|}{ 2nd Period } & \multicolumn{3}{|c|}{ 3rd Period } \\
\hline & & $\begin{array}{l}\text { Gaze in at } \\
\text { least one } \\
\text { direction }\end{array}$ & $\begin{array}{c}\text { No } \\
\text { gaze }\end{array}$ & $\begin{array}{c}\text { not } \\
\text { visible }\end{array}$ & $\begin{array}{l}\text { Gaze in at } \\
\text { least one } \\
\text { direction }\end{array}$ & $\begin{array}{c}\text { No } \\
\text { gaze }\end{array}$ & $\begin{array}{c}\text { not } \\
\text { visible }\end{array}$ & $\begin{array}{l}\text { Gaze in at } \\
\text { least one } \\
\text { direction }\end{array}$ & $\begin{array}{c}\text { No } \\
\text { gaze }\end{array}$ & $\begin{array}{c}\text { not } \\
\text { visible }\end{array}$ \\
\hline \multirow[t]{4}{*}{ Pedestrians } & Alone & 68.6 & 23.5 & 7.8 & 64.8 & 33.0 & 2.3 & 73.2 & 21.3 & 5.4 \\
\hline & Two & 60.7 & 32.1 & 7.1 & 60.5 & 28.9 & 10.5 & 67.0 & 22.9 & 10.1 \\
\hline & Three & 63.6 & 18.2 & 18.2 & 55.6 & 22.2 & 22.2 & 44.4 & 55.6 & 0.0 \\
\hline & Four or more & 0.0 & 0.0 & 1.0 & 50.0 & 16.7 & 33.3 & 40.0 & 46.7 & 13.3 \\
\hline \multirow[t]{4}{*}{ Cyclists } & Alone & 64.9 & 24.5 & 10.6 & 71.8 & 26.8 & 1.4 & 71.1 & 26.3 & 2.6 \\
\hline & Two & 58.6 & 24.1 & 17.2 & 56.3 & 25.0 & 18.8 & 65.4 & 11.5 & 23.1 \\
\hline & Three & 28.6 & 42.9 & 28.6 & 0.0 & 100 & 0.0 & 63.6 & 18.2 & 18.2 \\
\hline & Four or more & 62.5 & 37.5 & 0.0 & & & & 60.0 & 20.0 & 20.0 \\
\hline
\end{tabular}


ing the second period while the speed bump was in place. The total number of observed crossings on red was too low, as for the differences to be statistically significant.

Table 10: Total numbers of crossing on red per period

\begin{tabular}{lccc}
\hline & 1st Period & 2nd Period & 3rd Period \\
\hline Pedestrians & 3 & 0 & 8 \\
Cyclists & 3 & 0 & 2 \\
Total & 6 & 0 & 10 \\
\hline
\end{tabular}

Seven pedestrians and four cyclists began to cross immediately after the train passed through, without waiting for the end of the red light phase. On the other hand, four pedestrians and one cyclist were observed passing the level crossing during the red light phase (for example, to catch the train).

Table 11: Total numbers of crossing on red before and after passing of train

\begin{tabular}{lcc}
\hline & $\begin{array}{c}\text { Before train } \\
\text { passed through }\end{array}$ & $\begin{array}{c}\text { After train passed } \\
\text { through }\end{array}$ \\
\hline Pedestrians & 4 & 7 \\
Cyclists & 1 & 4 \\
Total & 5 & 11 \\
\hline
\end{tabular}

In addition, the observers noted other forms of road user misconduct in approaching and crossing the railway intersection. This includes the only conflict registered during the third period and through out the whole investigation period. A cyclist came out of the gas station located on the north western side of the level crossing to turn onto the sidewalk. A car driver who apparently expected that the cyclist would turn onto the road, had only little time to react because of his speed and was swerving over the centre line in order to avoid an accident and came to the other side of the road. This conflict could have been prevented by the speed bump which would have slowed down the car driver before reaching the location of the conflict.

Approaches of cyclists on the wrong side of the carriageway were observed during the first and third periods and crossing the road just before the intersection happened in all three recording periods.

During all three periods, pedestrians were distracted by conversations with other people, manipulating things like headphones, etc., or caring for a dog, which meant that they did not look before crossing the railway intersection. Also talking on the phone or texting led to unsafe behaviour when crossing during all three periods

Table 12 gives an overview of the erroneous behaviour of road users (which were not systematically evaluated). An X shows if such behaviour was observed during the evaluation period. Even though the frequency of this behaviour was rather small, it shows the problems which can occur at the level crossing. Especially the distractions due to conversations and other things, texting and talking to the phone were reasons that pedestrians were not looking before crossing the level crossing.

Table 12: Observed behaviour of different road user groups at different periods

\begin{tabular}{|c|c|c|c|c|c|c|}
\hline \multirow[b]{2}{*}{ Period } & \multicolumn{3}{|c|}{ Pedestrians } & \multicolumn{3}{|c|}{ Cyclists } \\
\hline & 1 & 2 & 3 & 1 & 2 & 3 \\
\hline $\begin{array}{l}\text { Approaching on the wrong } \\
\text { side of the road }\end{array}$ & & & & $\mathrm{X}$ & & $\mathrm{X}$ \\
\hline $\begin{array}{l}\text { Crossing the road directly } \\
\text { before the railway crossing }\end{array}$ & & & & $\mathrm{X}$ & $\mathrm{X}$ & $\mathrm{X}$ \\
\hline $\begin{array}{l}\text { Distracted by } \\
\text { conversations, dog or } \\
\text { manipulating things }\end{array}$ & $\mathrm{X}$ & $\mathrm{X}$ & $\mathrm{x}$ & & & \\
\hline Texting & $\mathrm{X}$ & $\mathrm{X}$ & $\mathrm{X}$ & & $\mathrm{X}$ & \\
\hline Talking on the phone & $\mathrm{X}$ & $\mathrm{X}$ & $\mathrm{x}$ & & & \\
\hline
\end{tabular}

\section{SUMMARY AND CONCLUSION}

One of the project goals was to develop a measurement technique which is not only analysing the behaviour (changes) of motorised vehicle drivers but also has the possibility to evaluate the behaviour of vulnerable road users in order to estimate the effectiveness of a traffic safety measures at level crossings. Within this article we showed that with the help of the combination of an infrared camera and a video camera several results can be analysed with regard to vulnerable road users. Furthermore, it became clear that the measurement technique can be used independently from the infrastructural situation and the type of protection (active or passive) at a level crossing.

Generally, vulnerable road users were crossing the railway mostly alone followed by crossing in pairs. Bigger groups were also observed but were more an exception like school classes or groups of recreational cyclists. 
With regard to the infrastructure situation, it became clear that most of the pedestrians were using the right sidewalk while most of the cyclists were using the road, despite the fact that an mixed sidewalk/ cycle path exists on the left side. As the mixed sidewalk/cycle path is quite narrow it seems that cyclists prefer to ride on the road to getting in conflict with other cyclists or pedestrians.

In order to see if the observed behaviour of (vulnerable) road users can be distinguished according to the error categories mentioned in the theory chapter and if there were any changes in the behaviour during the three measurements periods the following results are presented according to the different error categories.

\section{Source of error a) Information processing and distractions}

The question here is if road users were able to gather and process enough information about the level crossing so that they are crossing it in a safe way. Therefore, the gaze behaviour of vulnerable road users was analysed in order to see if they were looking before crossing a level crossing. This would be particularly important if a passive level crossing was to be evaluated. Furthermore, the assumption of the authors is that regardless if the level crossing is actively or passively secured (active secured - technical measures such barriers, light signals, passive secured - only with road signs and makings), road users should check, by looking right and left, if it is save to cross the level crossing.

The gaze behaviour of the vulnerable road users to the left and right hardly changed over the time and about two thirds of the pedestrians and cyclists were looking in at least one direction before crossing the railway. Nevertheless, due to the disturbance in the line of sight (house before the rail road crossing) most people were looking to the right in order to see the track behind the house. On the left side, the visibility was relatively good and could rather be covered by eye movements or peripheral vision. Nevertheless that this was not evaluated systematically. In a future study with the focus on vulnerable road user behaviour, this should be looked at more in detail (by using the same method). It could be concluded from the observations that the main reasons for not looking were that pedestrians were distracted by conversions, texting or talking on the phone.

When walking or cycling in pairs or in groups of three, people were looking less often compared to when walking alone. It seems that the members of the group relied on each other to look out or were more often distracted by talking to each other. Nevertheless, it became clear that such behaviour at a level crossing, if it wasn't actively protected with light signals, would not be ideal. As the house before the crossing prevents road users to have a good view on the tracks, there is a potential that road users might see a coming train too late.

Lower speeds also increase the time available for information processing. While the speeds of pedestrians are low enough for that, the speeds of cyclists are within a much broader range. It became clear that the speed bump also had an effect on those (faster) cyclists who were using the road. Given the fact that most of them rode around the speed bump, they had to slow down shortly before the speed bump.

Other possible distractions that can hinder information processing were observed. One of the reasons why pedestrians were not looking was because they were distracted by conversations with other people, handling things like headphones, etc. or caring for a dog. Also talking on the phone or texting led to unsafe behaviour while crossing. On the other hand, cyclists showed more often behaviour such as crossing the road either directly in front of or on the railway crossing itself, which makes it difficult to see what is coming from behind. This again would be even unsafer if the level crossing was not secured by a light signal.

\section{Source of error b) Assessment and decision error}

It is important that the road users decide correctly if the crossing is safe or not. Here the red light violations of vulnerable road users were analysed. Only during the period without the speed bump eleven pedestrians and five cyclists were crossing the rail road while the red light was activated. No one crossed while the red light was activated at the period with speed bump. Due to the low total numbers, it is not possible to ascribe that to the speed bump with certainty. Four pedestrians and one cyclist were crossing before the train passed through. It was observed that people were running in order to catch the train (which confirmed the results by Fertner (2009) and Raml, 2012) or were first waiting but crossed against red after some time (it seemed that the waiting time was too long which goes in hand with the results of Ellinghaus and Steinbrecher, 2006). 


\section{Source of error c) Action error}

Unintentional failure results could not be observed as well as deliberate violation of a rule (a red light crossing just before the train passed by). But the speeds of the road users, while the speed bump was in place, can be seen as mitigating potentially severe consequences of action error, also when VRU are involved. The only observed conflict during the whole investigation periods happened during a period without the speed bump, but could have been prevented by it as the speed of the car driver would have been much lower.

\section{SUGGESTIONS FOR IMPROVEMENT OF THE METHOD}

In order to keep the maintenance intervals as long as possible a hard disk with a high storage capacity should be used, If the cameras are not linked to a power grid it is recommended to use either as many batteries as possible or batteries with a high ampere hour capacity. With regard to the red light detection it is recommend to connect this directly to the camera systems in order to store the information together with the infrared data. In order to improve the evaluation of the gaze behaviour, on-site observations can be carried out with the disadvantage that it might influence the behaviour of the observed road users.

\section{COMMENTS TO THE READER}

Within the SESAM project speeds and the position of motorised vehicle were mainly evaluated by using the data of the infrared camera. We want to clarify that due to the fact that the focus of the TOTS special issue is on vulnerable road user we tried to emphasise this by not presenting any results regarding motorised vehicles or which were related to them (such as that speeds were declining by about $15 \mathrm{kph}$ with the speed bump in comparison to the periods without the speed bump, speeds over $40 \mathrm{kph}$ were completely erased in the period with the speed bump) as we had the feeling that these result would have taken away the attention from the main focus (vulnerable road users) of this article.

\section{REFERENCES}

Aigner-Breuss, Eva; Aleksa, Michael; Braun, Eveline; Machata, Klaus; Knowles, Daniela; Runda, Kerstin; Stefan, Christian; Tomasch, Ernst (2011). MANEUVER. Entwicklung von Maß- nahmen zur Vermeidung von Fehlverhalten an Eisenbahnkreuzungen mit Hilfe der Verkehrspsychologie. Ein Handbuch für PraktikerInnen und EntscheidungsträgerInnen.

Berg, W. D., Knoblauch K., Hucke W. (1982). Causal Factors in Railroad-Highway Grade Crossing Accidents, Transport Research Record 847

Caird, J. K., Creaser J. I., Edwards, C.J. and R. E. Dewar (2002), A Human Factors Analysis of Highway-Railway Grade Crossing Accidents in Canada. Montreal, Quebec, Transportation Development Centre Transport Canada

Dinhobel, G. und P. Lengger (2012). The Acceptance of red lights at level crossings. Ppt held at 12th Global Level Crossing and Trespass Symposium, London, 7th - 12th October 2012. in Aigner-Breuss, Eva; Aleksa, Michael; Braun, Eveline; Machata, Klaus; Knowles, Daniela; Runda, Kerstin; Stefan, Christian; Tomasch, Ernst (2011). MANEUVER. Entwicklung von Maßnahmen zur Vermeidung von Fehlverhalten an Eisenbahnkreuzungen mit Hilfe der Verkehrspsychologie. Ein Handbuch für PraktikerInnen und EntscheidungsträgerInnen.

Fertner, M. L. (2009). Verhalten auf Eisenbahnkreuzungen. Fehleinschätzungen der Risiken auf Eisenbahnkreuzungen durch die Straßenverkehrsteilnehmer. Zeitschrift für Verkehrsrecht 54.Jg., Heft 11/November 2009: 381-384.

Ellinghaus, D. und J. Steinbrecher (2006), Das Kreuz mit dem Andreaskreuz: Eine Untersuchung über Konflikte an Bahnübergängen. Hannover, Continental AG.

Grimm, H.G. (1988). Wahrnehmungsbedingungen und sicheres Verhalten im Straßenverkehr: Situationsübergreifende Aspekte. Bericht zum FP 8306 der BASt, Bereich Unfallforschung, Forschungsberichte Nr. 176, Bergisch Gladbach.

Nussbaumer, C.; Nitsche, P. (2007), Andreas: Überwachung von Eisenbahnkreuzungen. Gefördert aus den Mitteln des Österreichischen Verkehrssicherheitsfonds, Wien, Kuratorium für Verkehrssicherheit.

Meeker, F. L. and R. A. Barr (1989). An observational study of driver behavior at a protected railroad grade crossing as trains approach. Accid Anal Prev 21(3): 255-62.

Nussbaumer, C.; Nitsche, P. (2007), Andreas: Überwachung von Eisenbahnkreuzungen. Gefördert aus den Mitteln des Österreichischen Verkehrssicherheitsfonds, Wien, Kuratorium für Verkehrssicherheit.

Pripfl, J. (2009). Human Factors bei Eisenbahnkreuzungsunfällen: Ein Überblick über internationale Studienergebnisse. In: Gürtlich, G.H. \& Thann, O. (Hrsg.): Sicherheit von Eisenbahnkreuzungen. Tagungsband 2008 und Ergebnisse der Arbeitsgruppen 2009. Österreichische Verkehrswissenschaftliche Gesellschaft, ÖVG Spezial Band 94, Wien, 2009: 39-45.

Rail Safety \& Standards Board, RSSB (2008). Development of a level crossing risk management toolkit. Operations. Summary report. RSSB LTD., UK 2008.

Rail Safety \& Standards Board, RSSB (2011a). Road user survey and eye tracking trials. RSSB Research Programme. Operations and Management. Re-search into signs and signals at level crossings. Annex report II. http://www.rssb.co.uk/sitecollectiondocuments/pdf/reports/research/T756_anx2_final. pdf [20.11.2012] 
Rail Safety \& Standards Board, RSSB (2011b). A Review of human factors litera-ture on the design of information and warnings. RSSB Research Pro-gramme. Operations and Management. Research into signs and signals at level crossings. Annex report I. http://www.rssb.co.uk/sitecollectiondocuments/pdf/ reports/research/T756_anx1_final.pdf [20.11.2012]

Raml, R. (2012a). Eisenbahnkreuzungen - Pkw-Fahrer. Befragungsergebnisse. IFES (Institut für Empirische Sozialforschung) im Auftrag für das Kuratorium für Verkehrssicherheit. Wien (unveröffentlicht). in Aigner-Breuss, Eva; Aleksa, Michael; Braun, Eveline; Machata, Klaus; Knowles, Daniela; Runda, Kerstin; Stefan, Christian; Tomasch, Ernst (2011). MANEUVER. Entwicklung von Maßnahmen zur Vermeidung von Fehlverhalten an Eisenbahnkreuzungen mit Hilfe der Verkehrspsychologie. Ein Handbuch für PraktikerInnen und EntscheidungsträgerInnen.

Raml, R. (2012b). Eisenbahnkreuzungen - Anrainer. Befragungsergebnisse. IFES (Institut für Empirische Sozialforschung) im Auftrag für das Kuratorium für Verkehrssicherheit. Wien (unveröffentlicht). in Aigner-Breuss, Eva; Aleksa, Michael; Braun, Eveline; Machata, Klaus; Knowles, Daniela; Runda, Kerstin; Stefan, Christian; Tomasch, Ernst (2011). MANEUVER. Entwicklung von Maßnahmen zur Vermeidung von Fehlverhalten an Eisenbahnkreuzungen mit Hilfe der Verkehrspsychologie. Ein Handbuch für PraktikerInnen und EntscheidungsträgerInnen.

Skládaný, P, et al. (2016), RÜTTLEX - Entwicklung von Rüttelstreifen zur Vermeidung von Fehlverhalten an Eisenbahnkreuzungen - Ergebnisbericht zum Forschungsprojekt

Wigglesworth E. C., (1976). Human factors in road-rail crossing accidents. Monograph. Victoria, Ministry of Transport.

\section{Websites:}

https://shop.neuhauser-vt.com/c/47/a/10698/Warn--undTemposchwellen/Tempo-Hemmschwelle-bis-10-km-h-schwarz. html;JSESSIONID=a44a0bf5-48d5-47b9-b85f-54d69f88f646 last checked in March 2019 